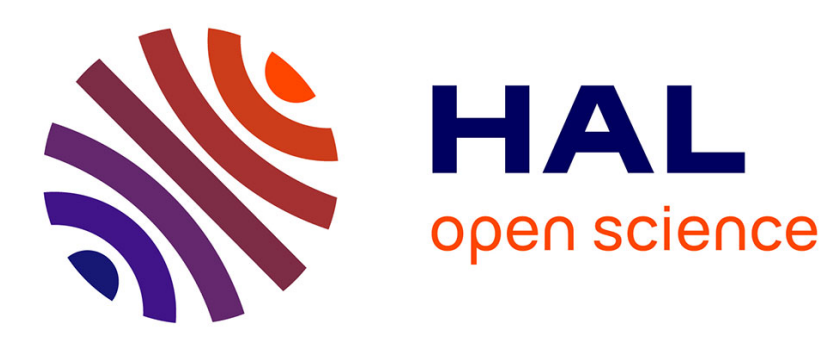

\title{
Temperature dependence of the spin-orbit coupling and energy gap in cuprous bromide
}

S. Lewonczuk, J.G. Gross, J. Ringeissen

\section{To cite this version:}

S. Lewonczuk, J.G. Gross, J. Ringeissen. Temperature dependence of the spin-orbit coupling and energy gap in cuprous bromide. Journal de Physique Lettres, 1981, 42 (4), pp.91-94. 10.1051/jphyslet:0198100420409100 . jpa-00231881

\section{HAL Id: jpa-00231881 https://hal.science/jpa-00231881}

Submitted on 1 Jan 1981

HAL is a multi-disciplinary open access archive for the deposit and dissemination of scientific research documents, whether they are published or not. The documents may come from teaching and research institutions in France or abroad, or from public or private research centers.
L'archive ouverte pluridisciplinaire HAL, est destinée au dépôt et à la diffusion de documents scientifiques de niveau recherche, publiés ou non, émanant des établissements d'enseignement et de recherche français ou étrangers, des laboratoires publics ou privés. 


\title{
Temperature dependence of the spin-orbit coupling and energy gap in cuprous bromide
}

\author{
S. Lewonczuk, J. G. Gross and J. Ringeissen \\ Laboratoire de Spectroscopie et d'Optique du Corps Solide (*), Université Louis-Pasteur, 5, rue de l'Université, 67000 Strasbourg, \\ France
}

(Reçu le 5 décembre 1980, accepté le 5 janvier 1981)

\begin{abstract}
Résumé. - Le spectre de réflexion de $\mathrm{CuBr}$ est mesuré sur des cristaux clivés dans une grande plage spectrale et à différentes températures comprises entre 6 et $300 \mathrm{~K}$. La séparation spin-orbite (SO), la largeur de la raie excitonique $Z_{12}$ ainsi que la variation du gap fondamental $E_{\mathrm{g}}$, sont étudiées en fonction de la température. La séparation (SO) est indépendante de la température, la demi-largeur de $Z_{12}$ croît linéairement avec $T^{2}$, tandis que $E_{\mathrm{g}}$ a un coefficient de température positif.
\end{abstract}

\begin{abstract}
The reflection spectrum of $\mathrm{CuBr}$ has been measured on cleaved crystals, in a wide spectral range at various temperatures between 6 and $300 \mathrm{~K}$. The spin-orbit splitting (SO), the half-width of the $Z_{12}$ exciton line and the fundamental energy gap $E_{\mathrm{g}}$ are studied as a function of temperature. The (SO) separation is found to be independent of the temperature; the half-width of $Z_{12}$ increases linearly with $T^{2}$ whereas $E_{\mathrm{g}}$ has a positive temperature coefficient.
\end{abstract}

The physical properties of the cuprous halides differ from those of other isoelectronic zinc blende compounds. This is due to the contribution of the $3 \mathrm{dCu}^{+}$orbitals in the valence band (VB). If $\alpha$ represents the percentage of the $\mathrm{npX}^{-}$orbitals at the maximum of the (VB), the spin-orbit splitting $\Delta_{\text {so }}$ can be expressed as :

$$
\Delta_{\mathrm{SO}}=\frac{3}{2}\left[\alpha \Delta_{\mathrm{npX}^{-}}-(1-\alpha) \Delta_{3 \mathrm{dCu}^{+}}\right]
$$

where $\Delta_{\mathrm{npX}}{ }^{-}$and $\Delta_{3 \mathrm{dCu}}+$ are the atomic spin-orbit splittings [1]. From experimental values of $\Delta_{\text {so }}$, this relation indicates that the contribution of $p$ like wave functions to the (VB) increases from $\mathrm{CuCl}$ to $\mathrm{CuI}$.

On the other hand, for a given crystal, we can also expect that the overlap of the $p$ and $d$ wave functions changes as the interatomic distance is varied through changes in temperature.

In $\mathrm{CuCl}$, the splitting of the $Z_{12}$ and $Z_{3}$ excitons, originating respectively from $\Gamma_{8}$ and $\Gamma_{7}$ of the spinorbit split valence band maximum has been found to be temperature independent by Kaifu et al. [2]. In the present work, we study the temperature dependence, in $\mathrm{CuBr}$, of :

(*) Associé au C.N.R.S. no 232. (i) the splitting of the $Z_{12}$ and $Z_{3}$ exciton lines, (ii) the half-width of the $Z_{12}$ line,

and (iii) the temperature coefficient of the energy gap.

In this study, we measure the excitonic reflection spectrum of $\mathrm{CuBr}$ between $6 \mathrm{~K}$ and $300 \mathrm{~K}$. The Kramers-Krönig (K.K.) inversion of these curves gives the spectral position and the shape of the $Z_{12}$ exciton line. We first consider if the spin-orbit splitting is modulated by thermal expansion or dynamic hybridization. Second, the temperature dependence of $E_{\mathrm{g}}$ is presented and compared with the recent theoretical calculation of the Debye-Waller factor [3].

1. Experimental. - The reflection spectra were measured on (110) cleaved faces of single crystals. The samples are cooled by immersion in gaseous helium. Variations in temperature are obtained by heating the helium gas and by controlling the helium gas flow. The temperature can be stabilized to within $1 \mathrm{~K}$ for $T<150 \mathrm{~K}$, and to within $2 \mathrm{~K}$ for $T>150 \mathrm{~K}$. The experimental points are digitized, and the reflection coefficient and the K.K. integral are calculated by a minicomputer. At all temperatures, the reflection coefficient is normalized to a theoretical value determined by the Fresnel relation at $5460 \AA(2.27 \mathrm{eV})$ for which the refractive index is measured on a $\mathrm{CuBr}$ prism at room temperature. 
We assume that the absorption coefficient is negligible at this wavelength, and that the refractive index does not change with temperature.

2. Results and discussion. - The reflection spectra (Fig. 1) have been measured in the spectral range from $2 \mathrm{eV}$ to $6.5 \mathrm{eV}$. For clarity, we present the spectra measured in the excitonic range at four different

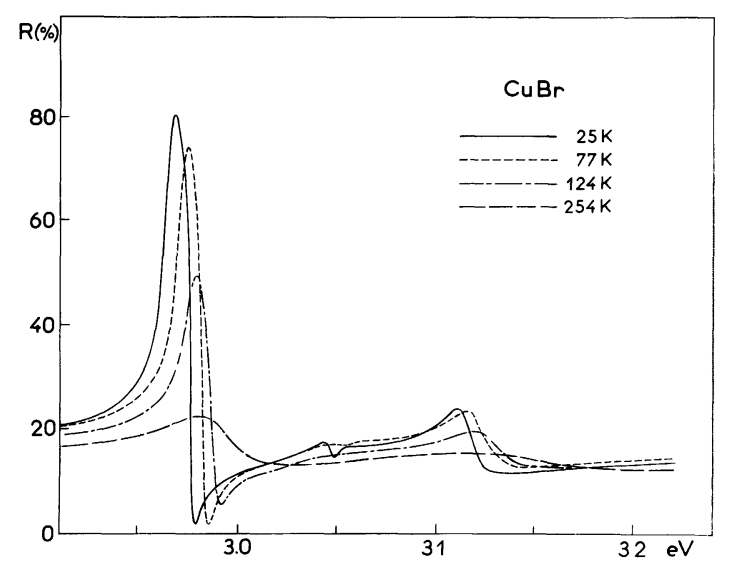

Fig. 1. - Reflection spectra of $\mathrm{CuBr}$ at four different temperatures. The spectra have been measured between 2 and $6.5 \mathrm{eV}$. For clarity, only a limited spectral range is shown.

temperatures. The corresponding absorption curves, obtained by Kramers-Krönig analysis, are shown in figure 2 for the same temperatures. The position of the maxima of the absorption coefficient $\left(K_{\max }\right)$

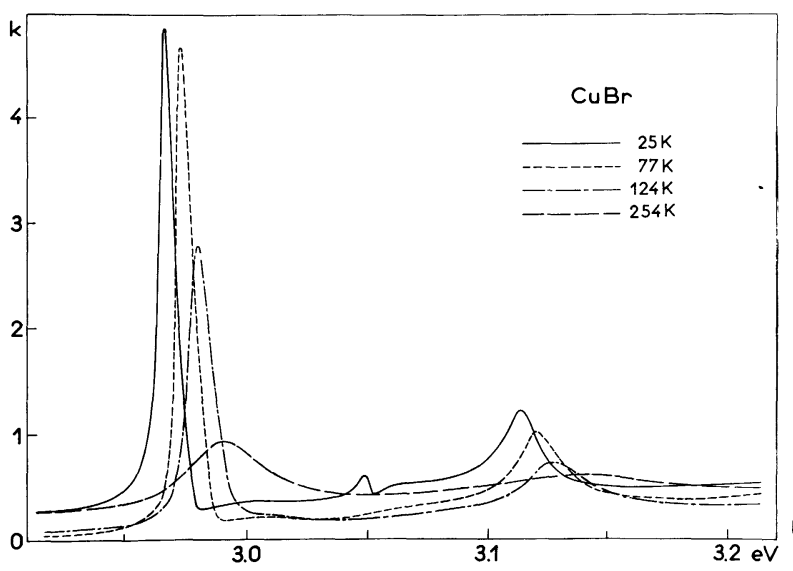

Fig. 2. - Absorption spectra of $\mathrm{CuBr}$ at different temperatures calculated by the Kramers-Krönig relation.

for $Z_{12}$ and $Z_{3}$ are plotted in figure 3, as a function of temperature. The variation of the $K_{\max }$ position with temperature can be approximated for both $Z_{12}$ and $Z_{3}$ with parabolic curves obtained by a least squares fit (neglecting the $6 \mathrm{~K}$ data point).

The half-width of the $Z_{12}$ exciton line is plotted in figure 4 versus $T^{2}$. This plot is limited to temperatures below $230 \mathrm{~K}$. At higher temperatures the determination of the width is uncertain, because of the difficulty in choosing $K_{\max }$ and the uncertainty

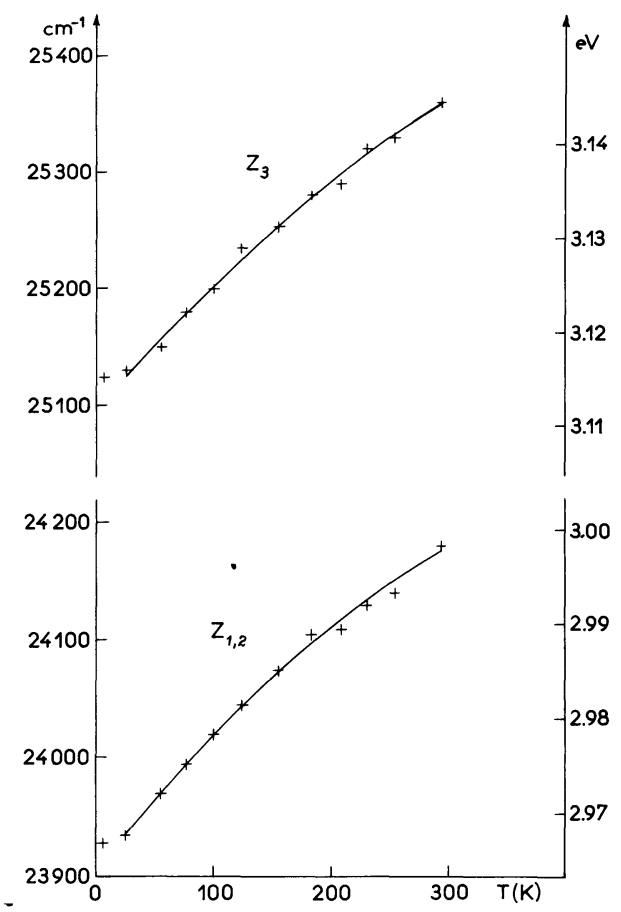

Fig. 3. - The position of the $Z_{12}$ and $Z_{3}$ excitonic lines as a function of temperature. The plus signs are the peak positions $\left(K_{\max }\right)$ derived from the experimental data through the KramersKrönig inversion. The full lines are parabolic curves obtained by a least squares fit.

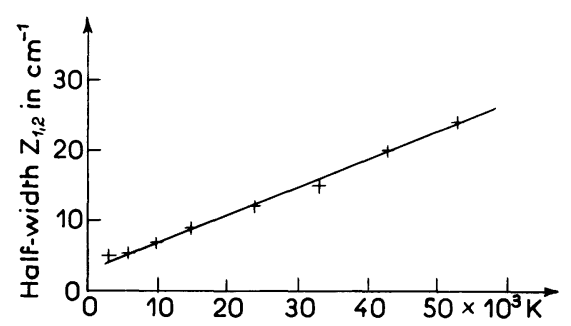

Fig. 4. - The half-width of the $Z_{12}$ line plotted versus $T^{2}$.

concerning the absorption continuum background. We consider only the $Z_{12}$ line, because $Z_{3}$ is superposed on higher order exciton or satellite lines [4], and its half-width varies in a more complicated way.

2.1 SPLitTing OF THE EXCITON LINES $Z_{12}$ AND $Z_{3}$ WITH LATTICE EXPANSION. - As can be seen in figure 3, the $Z_{12}, Z_{3}$ splitting remains practically constant with temperature. The increase of about $0.8 \mathrm{meV}$ in the splitting, derived from the fitted curves, when the temperature decreases from 300 to $25 \mathrm{~K}$, is within our experimental error estimated to be on average about $4 \mathrm{meV}$, considering each experimental point separately. This means that the change in the mixing ratio of $p$ and $d$ orbitals is negligible as the interatomic distance decreases with thermal contraction.

This result can be checked, qualitatively, by comparing it with the effect of hydrostatic pressure. When the temperature is lowered from 300 to $25 \mathrm{~K}$, the decrease in volume of the unit cell characterized by $\mathrm{d} V / V$ is about $7.4 \times 10^{-3}$ from the fractional 
decrease of the lattice parameter, given as $2.46 \times 10^{-3}$, in reference [5]. Using the known compressibility, we can estimate the pressure, necessary to cause such a decrease in lattice parameter at constant temperature. The bulk modulus is on average about $4 \times 10^{5}$ bar [6], which leads to a pressure of about 2900 bar. The experimental results reported in [7] show that this pressure will induce an increase in the $Z_{12}, Z_{3}$ splitting of about $1.4 \mathrm{meV}$. This variation is in agreement with what we observe. According to equation (1) the corresponding change in the $\mathrm{p}$ wave function contribution, $\Delta \alpha / \alpha$, is less than $5 \times 10^{-3}$.

2.2 HALF-WIDTH OF $Z_{12}$ AND THE DYNAMIC HYBRIDIZATION EFFECT. - The interatomic distance is also modulated by thermal vibration.

The relative fall of such a modulation when the temperature is decreased from $300 \mathrm{~K}$ to $5 \mathrm{~K}$ may be estimated to be roughly about $4 \times 10^{-2}$ from the variation in the root mean square displacement of the $\mathrm{Cu}^{+}$ions from $0.161 \AA$ to $0.055 \AA$ and the $\mathrm{Br}^{-}$ ions from $0.189 \AA$ to $0.061 \AA$ [8].

This relative decrease is much more important than that induced by lattice contraction. In the preceding discussion, we compared the effect of a decrease in temperature at constant pressure to that of an increase in hydrostatic pressure at constant temperature. In the two experiments the lattice contraction is the same, but in the former, there is superimposed the decrease of the lattice vibration amplitude. The fact that the (SO) splitting remains practically constant is a preliminary indication, that dynamic hybridization does not occur.

Such an hybridization should also give rise to an anomalous broadening of the exciton lines, as is believed to explain the temperature dependence of electron density curves in photoemission experiments [9].

Figure 4 shows that, between $25 \mathrm{~K}$ and $230 \mathrm{~K}$, the experimental half-width of $Z_{12}$ varies linearly with $T^{2}$, according to Toyozawa's theory for phononexciton interactions [10].

Thus our observations show that there is no reason to consider that dynamic hybridization plays a role in the optical spectra of $\mathrm{CuBr}$.

We conclude that for $k=0$, the mixing ratio of $\mathrm{p}$ and $\mathrm{d}$ functions, is affected neither by thermal expansion, nor by thermal vibrations. Hence the anomalous temperature dependence of the energy band gap requires a different explanation.

2.3 TEMPERATURE DEPENDENCE OF THE ENERGY BAND GAP. - The temperature dependence of an energy level $E_{\mathrm{n}}$ at constant pressure is given as follows [11] :

$$
\left.\frac{\partial E_{\mathrm{n}}}{\partial T}\right|_{p}=\left(\frac{1}{\Omega} \frac{\partial \Omega}{\partial T}\right)_{p}\left(\Omega \frac{\partial E_{\mathrm{n}}}{\partial \Omega}\right)_{T}+\left(\frac{\partial E_{\mathrm{n}}}{\partial T}\right)_{v}
$$

where :

$\left(\frac{1}{3 \Omega} \frac{\partial \Omega}{\partial T}\right)_{p}$ is the thermal expansion coefficient,

$3 \Omega\left(\frac{\partial E_{\mathrm{n}}}{\partial \Omega}\right)_{T}$ is the deformation potential,

$\left(\frac{\partial E_{\mathrm{n}}}{\partial T}\right)_{v}$ is the electron-phonon interaction term.

Usually, the effect of the electron-phonon interaction is more important than that due to the thermal expansion [12]. The electron-phonon interaction gives rise to the self-energy term and to the Debye-Waller factor [13]. The self-energy term contains intraband and interband contributions. The intraband contribution always gives rise to a negative temperature coefficient of the forbidden energy gap, while the interband contribution gives a positive temperature coefficient [14]. On the other hand, the Debye-Waller effect may give a positive or a negative temperature coefficient depending upon the relative changes in the positions of the minima of the conduction band $\left(E_{\mathrm{c}}\right)$ and the maxima of the valence band $\left(E_{\mathrm{v}}\right)$.

Recently, the Debye-Waller effects on $\left(E_{\mathrm{c}}\right)$ and $\left(E_{\mathrm{v}}\right)$ of $\mathrm{CuCl}$ and $\mathrm{CuBr}$ have been studied theoretically. This calculation gives $\partial E_{\mathrm{g}} / \partial T \simeq 3.3 \times 10^{-3}$ and $2.8 \times 10^{-3} \mathrm{eV} / \mathrm{K}$ for $\mathrm{CuCl}$ and $\mathrm{CuBr}$ respectively. Though these positive slopes are in agreement with experimental measurements, they are unfortunately ten times larger than the measured values. Kaifu et al. [2] found $\partial E_{\mathrm{g}} / \partial T \simeq 2 \times 10^{-4} \mathrm{eV} / \mathrm{K}$ for $\mathrm{CuCl}$ and we find $\partial E_{\mathrm{g}} / \partial T$ is $\sim 1 \times 10^{-4} \mathrm{eV} / \mathrm{K}$ for $\mathrm{CuBr}$ (Fig. 3). The disagreement between the experimental and calculated values is not surprizing. In a general review Allen and Heine have shown that there is a possibility of cancellation of different terms in the electron-phonon interaction [15]. To understand the phenomenon correctly, one needs to calculate all the different contributions. It is quite possible that the self-energy contribution is as important as the Debye-Waller effect, but is of opposite sign.

Acknowledgments. - We wish to thank Dr. M. A. Khan for a very close collaboration and Prof. M. Sieskind for useful discussions. 


\section{References}

[1] Cardona, M., Phys. Rev. 129 (1963) 69.

[2] KaIfu, Y., Komatsu, T., Phys. Status Solidi 48 (1971) K 125.

[3] Khan, M. A., Philos. Mag. 42 (1980) 565.

[4] Ringeissen, J., Coret, A., Nikitine, S., Localized Excitations in Solids (Plenum Press) 1968, p. 297.

[5] ShaAke, H. F., AFCRL Report no 69-0538 (quoted by PeNDL et al., 1972).

[6] Hanson, R. C., Hallberg, J. R., Schwab, C., Appl. Phys. Lett. 21 (1972) 490.

[7] Anthony, J. B., Brothers, A. D., Lynch, D. W., Phys. Rev. B 5 (1972) 3189.

[8] Hoshino, S., Fujil, Y., Harada, J., Axe, J. D., J. Phys. Soc. Japan 41 (1976) 965.
Prévot, B., Carabatos, C., Schwab, C., Hennion, B., Moussa, F., Solid State Commun. 13 (1975) 1725.

[9] Bauer, R. S., Lin, S. F., Spicer, W. E., Phys. Rev. B 14 (1976) 4527.

[10] Toyozawa, Y., Progr. Theor. Phys. 20 (1958) 53.

[11] Schluter, M., Martinez, G., Cohen, M. L., Phys. Rev. B 12 (1975) 650.

[12] Tsay, Y. F., Gong, B., Mitra, S. S., Vetelino, J. F., Phys. Rev. B 6 (1972) 2330.

[13] Baumann, K., Phys. Status Solidi (b) 63 (1974) K 71.

[14] Keffer, C., Hayes, T. M., Bienenstock, A., Phys. Rev. B 2 (1970) 1966

[15] Allen, B., Heine, V., J. Phys. C, Solid State Phys. 9 (1976) 2305. 